\title{
A Design by Any Other Name Would Be So Delightful
}

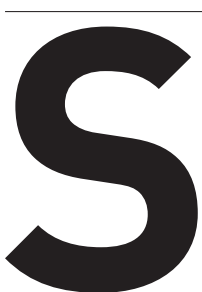
everal ago I attended the UXPA conference. The theme was "We're not there yet." After 26 years as an interaction, UI, and UX designer, my first reaction was joy, at the validation that I wasn't alone in my perception of my role on a product. My next reaction was despair, that well, I am not alone in my perception of UX and my role, and that this issue is much larger than just myself. The message was "We have a ways to go.” I began thinking about the perception of UX and design and how it could be better promoted to move UX along, to get us "there," starting within my own organization and considering my past experiences.

There is still plenty of confusion over exactly what UX is, and a great misperception that it is visual design. Although the word design means "to plan and make decisions about (something that is being built or created)," somehow it is still very much perceived as creating only visual solutions. I still hear things like "Well I am the PM" or "Oh, I thought you were the visual designer" or "When will we see pictures?" and “This looks great."

Viewing the final product simply as images of what you see on the screen, in a visual pleasing way, is a misperception of what UX design is and how it contributes to the product. The fact is that those screens are actually sets of complex workflows, technology, and interactions that are the result of months of research, including customer visits, interviews, cross-group work with services or finance teams, fleshing out complex workflows, and resolving implementation issues with development, all in order to negotiate the way to the best end-user experience possible - aka, what you are seeing on those screens.

I took a step back and started observing what transpires in the typical product-creation process. I observed something like the following: Marketing and Product have an idea or have received a customer request, or Customer Support or Design has unearthed some pain points in the product. A developer, a designer, and maybe a product manager get together to whiteboard and exchange ideas. Once this small, dynamic group feels solid on a concept, the designer goes off and plans out the layout and interaction for each of the screens and the workflows that build the relationships between them, to ensure that users are able to accomplish their tasks. Some customer interviews or visits may take place, and some usability testing, to gain feedback on the ideas, may occur. Therein lies the problem. The concept that this entire process is the design is what is being missed. The final step of engaging a visual designer is where the focus sits.

The premise of design thinking is to address exactly this: All team members, regardless of their role, are responsible for the design because the process is the design; the screens and the experience are the end result. All of those involved in creating the product seem to understand that they are designing the product but still consider the designer mainly responsible for making the pictures of the decisions that have been made along the way.

As I thought about this, I wondered how we can change this perception of design and have it be seen as the process, not just the end result. I began by considering the semantics of how I refer to and use the word design in my everyday work.
Semantics count and influence the way in which design is perceived. When the research phase for a feature or an experience is happening, I don't refer to it as "the research phase of the design.” Rather, I refer to it as “conducting design research.” Why? If I say, "I am working on the research phase of the design," what is heard and thought of as the design, as an end result, is a picture. The emphasis is on design and on the idea that a picture is being tested to see if it works or how to make it better. And what is communicated back might sound something like, “OK, that's great, but when will you have the pictures ready?" Because the focus is still on the end result, which is what people are going to see, and not on the research and process that help drive the end result. Getting the team to focus on the journey of the process, and to value this, is the goal. To shift the emphasis to the research portion of the process, saying, "I am in the design research phase," may be subtle, but now it's a reference to design with the focus on a portion of the process: the research.

I also looked at how I've worked with teams to create product designs. One thing I noticed was that we tend to plan around the stages of design but talk about the final artifacts - the pictures - as the design goal, rather than referring to the design process and the experience it creates as the goal. For example, when I begin generating wireframes, I no longer refer to the wireframes as "early designs" or “wireframes of the designs.” Again, what we say matters. Instead, I refer to these as "early product/experience concepts" or simply “concept wireframes," excluding the word design. Why? Because the wireframes are often viewed as final and then 


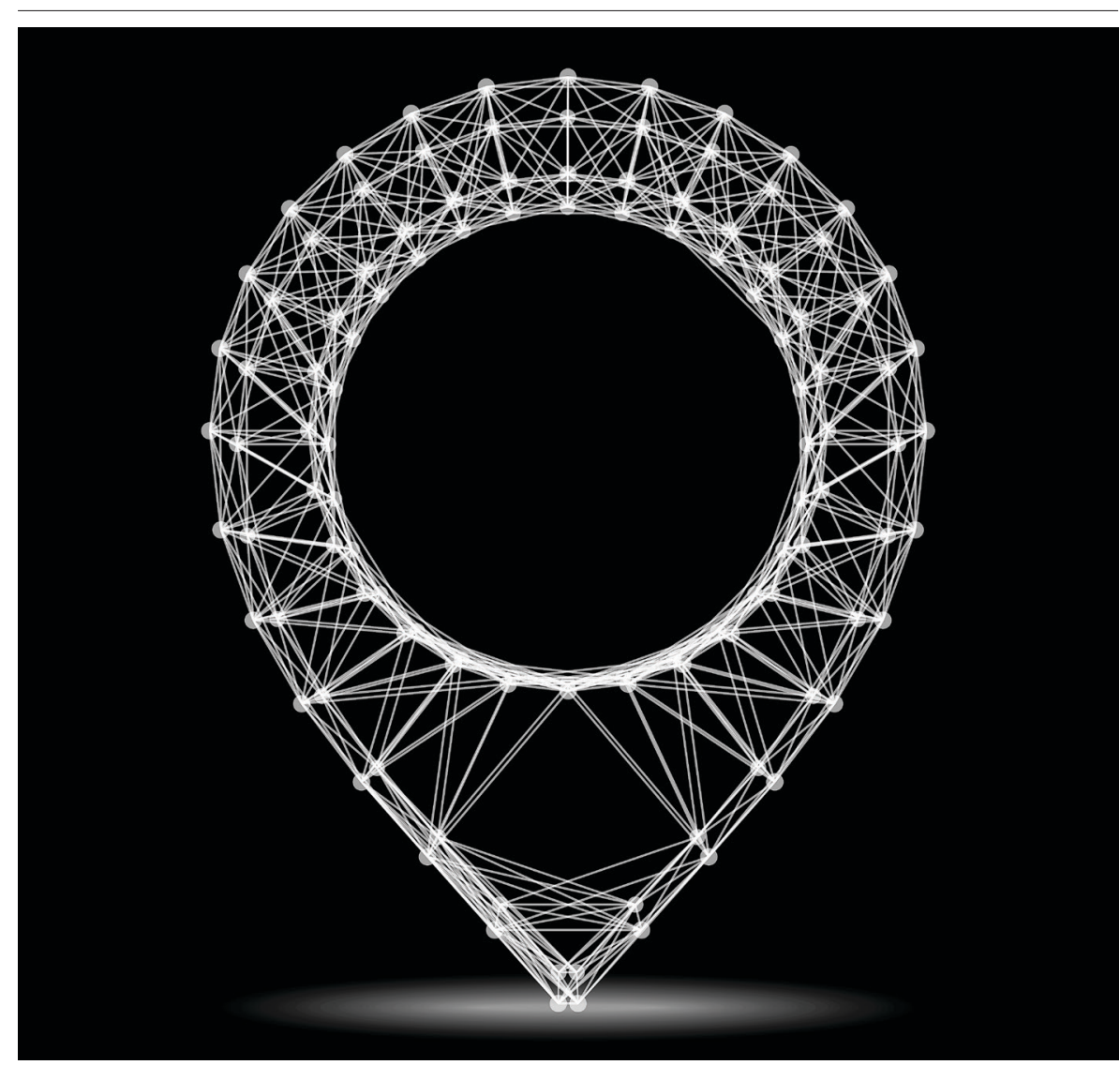

a push to have them look better unfolds. The words and the semantics of the words count. They affect whether or not design is perceived as inconsequential, and they are part of how we educate teams that design is the process, the journey to the solution.

I have been trying this approach. I'm making a conscious effort to talk about the various stages of product creation in terms of how the process contributes to the final outcome of the product and the experience users have with the product, rather than referring to any part of the process as the design, as if the design is this ultimate end product that magically appears. An example: When referring to the design research, I explain how research is a way to understand what the users are expecting out of the product or how workflows need to be created. Because these things form the z backbone of identifying how the users move through the product to accomplish tasks, or how the technology and data architecture contribute to when and how users see information and interact with it.

As creators, collectors of ideas and possibilities, the words we choose to use, and how we use them, can elevate our conversations away from the end results and toward the process and the journey. That is the heart of the design.

It is perhaps a statement of the obvious, but worth emphasizing, that the forms or structures of the immediate world we inhabit are overwhelmingly the outcome of human design. They are not inevitable or immutable and are open to examination and discussion. Whether executed well or badly (on whatever basis this is judged), designs are not determined by technological systems, or any other objective source. They rvesult from the decisions and choices of human beings. While the influence of context and circumstance may be considerable, the human factor is present in decisions taken at all levels in design practice.

\section{—John Heskett}

(1) Monica Granfield is a user experience strategist at Go Design LLC.

$\rightarrow$ monicagrandacomcast.net

() http://interactions.acm.org/blog/ author/8593/Monica\%20Granfield processes, social structures, or economic

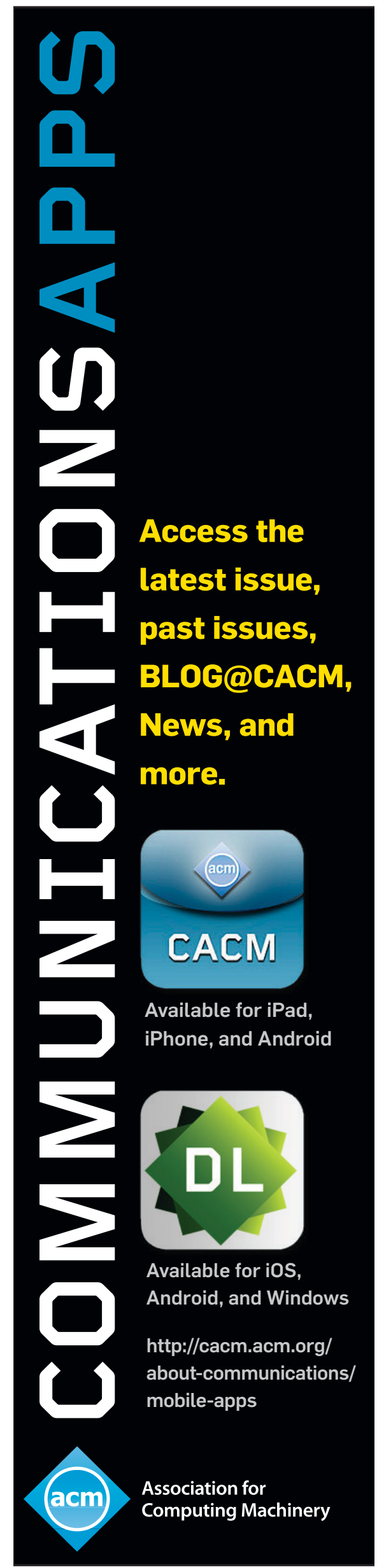

DOI: 10.1145/3050245 COPYRIGHT HELD BY AUTHOR 